\title{
Inhalt des 5. Jahrganges
}

L u igi Belloni, Immatrikulations- und Testaturkunde des Tessiner Augenarztes Pietro Magistretti (1765-1837) . . . . . . 34

He in ri c h B u e B, Conrad Geßners Beziehungen zu Basel . . . 1

F. P. F is c h e r, Ủber Lichtenbergs Anteil an der Ophthalmologie seiner Zeit . . . . . . . . . . . . . . . . 74

H a s Fischer, Schweizerische Bibliographie der Geschichte der Naturwissenschaften und der Medizin 1944-1946, I. Serie . . . 43

K. J. F r a n k l i n, William Harvey-a Speculative Note . . . . 70

P. Jun g, Der Stadtarzt Dr. Sebastian Schobinger in St. Gallen . 57

J. H. Rille, Aus der Geschichte der Pellagra im Südtirol und in der

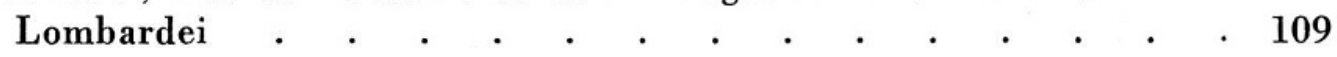

J. Stre be l, Analytische Studie über die paracelsische Ursprache . $\quad 30$

J. S t r e bel und D. Rit t me ye r, Neues vom St. Galler Schobinger-

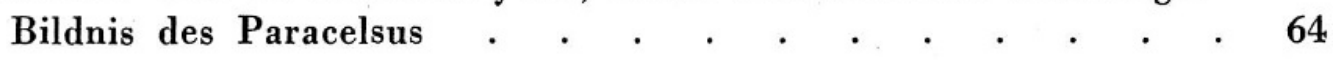

\section{Buchbesprechungen}

Archives Internationales d'Histoire des Sciences, Tome XXVII (H. Fischer)

Lychnos, Jahrbuch der Schwedischen Gesellschaft für Geschichte der Wissenschaften, Band 1946-1947 (H. Fischer) . . . . . $\quad 125$

Nova Acta Paracelsica. IV. Jahrbuch der Schweizerischen Paracelsus-Ge-

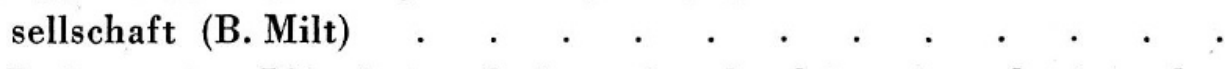

Jean Pelseneer, L'évolution de la notion de phénomène physique des primitifs à Bohr et Louis Broglie (André Mercier) . . ..

Studies and Essays in the History of Science and Learning offered in Homage to $\mathrm{G}$ e org e S a r t on (H. Fischer) . . . . . . . 124

Inhaltsverzeichnis zu Jahrgang 5 . 